\title{
Bifurcation of Health Policy Regimes: A Study of Sleep Apnea Care and Benefits Coverage in Saskatchewan
}

\author{
Bifurcation des régimes de politiques de santé : étude \\ des soins pour l'apnée du sommeil et des couvertures \\ d'assurance en Saskatchewan
}

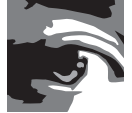 \\ GREGORY P. MARCHILDON, PhD, MA, JD, BA \\ Professor and Ontario Research Chair in Health Policy and System Design \\ Institute of Health Policy, Management and Evaluation, University of Toronto \\ Toronto, ON \\ CAROLINE A. BECK, MPP, BHSC \\ Johnson-Shoyama Graduate School of Public Policy \\ University of Regina \\ Regina, SK \\ TARUN R. KATAPALLY, PhD, MSC, BA \\ Assistant Professor, Johnson-Shoyama Graduate School of Public Policy \\ University of Regina \\ Regina, SK \\ SYLVIA ABONYI, PHD, MA, BSC \\ Associate Professor, College of Medicine \\ University of Saskatchewan \\ Saskatoon, SK \\ JAMES A. DOSMAN, MD, MA, BSC \\ Distinguished Research Chair, Canadian Centre for Health and Safety in Agriculture \\ College of Medicine, University of Saskatchewan \\ Saskatoon, SK \\ JO-ANN EPISKENEW, PHD, MA, BA* \\ Director, Indigenous Peoples Health Research Centre \\ Professor, University of Regina \\ Regina, SK
}

*Professor Episkenew passed away on February 18, 2016

HEALTHCARE POLICY Vol.12 No.4, 2017 [69] 


\begin{abstract}
Background: A complex, poorly understood bifurcated health policy regime exists for Canada's First Nations people for extended health benefits coverage. This research adds to a small body of literature on the regime's impact on access and quality of care and its role in perpetuating health inequities in First Nations populations.

Methods: Using a case study of sleep apnea care in Saskatchewan, we identified issues of health service access and coverage through a literature review of extended benefits programs, legislation and policies and through $10 \mathrm{key}$ informant interviews with federal and provincial extended benefit program administrators and sleep medicine physicians.

Results: Important access and coverage differences were found for First Nations populations, many of which were recognized by federal and provincial policy makers. Despite these, government respondents recommended few policy ameliorations, perhaps due to system complexities, constitutional constraints or political sensitivities.

Conclusions: We suggest three policy options to ameliorate current hardships wrought by this policy bifurcation.
\end{abstract}

\title{
Résumé
}

Contexte: Il existe un régime de politiques de santé bifurqué, complexe et peu compris pour les peuples des Premières Nations du Canada quant à l'assurance maladie complémentaire. Cette recherche s'ajoute au peu de littérature portant sur l'impact du régime sur l'accès aux soins et la qualité des soins et sur son rôle dans la perpétuation des iniquités en matière de santé pour les peuples des Premières Nations.

Méthode: Dans une étude de cas sur les soins pour l'apnée du sommeil en Saskatchewan, nous avons repéré des enjeux liés à l'accès aux services de santé et au régime d'assurance, et ce, (i) par une revue de la littérature sur les régimes d'assurance maladie complémentaires, la législation et les politiques et (ii) par 10 entrevues menées auprès d'administrateurs des programmes fédéral et provincial d'assurance maladie complémentaire et auprès de médecins spécialistes du sommeil. Résultats: On a observé d'importantes différences en matières d'accès aux services et de couverture pour les peuples des Premières Nations, dont plusieurs sont reconnues par les responsables de politiques fédéraux et provinciaux. Malgré cela, les répondants du gouvernement ont peu recommandé de politiques d'amélioration, peut-être en raison des complexités du système, des contraintes constitutionnelles ou des sensibilités de nature politique.

Conclusion: Nous présentons trois propositions de politiques visant l'amélioration des difficultés qu'engendre cette bifurcation politique.

\section{Introduction}

Throughout the world, particularly in settler societies such as Australia, Canada, New Zealand and the US, Indigenous populations have lower health status and poorer health outcomes than 
the majority population. And although Indigenous health status, as measured by mortality and morbidity, has improved over time, this gap in health status has persisted (Gracey and King 2009). While there are multiple and complex reasons for this persistent outcome, research has tended to focus on the non-medical determinants of health (King et al. 2009).

The purpose of this research is to explore a potential medical determinant of health, specifically access to a set of medical goods and services not deemed by provincial governments to be universally "insured services" as defined by the Canada Health Act and provincial Medicare laws and regulations (Health Canada 2017). As a consequence, registered Indians ${ }^{1}$ and recognized Inuit, ${ }^{2}$ who form the majority of Indigenous peoples of Canada, are excluded from provincial and territorial extended health benefit coverage. The federal government legally defines the Indigenous peoples of Canada as "Aboriginal". The Canadian Constitution Act of 1982 categorizes Aboriginal people in Canada into the following three groups: First Nations, Métis and Inuit.

While excluded from provincial and territorial extended health coverage, the majority (but not all) First Nations people and Inuit, classified by the federal government as registered Indians and recognized Inuit citizens, are eligible for coverage provided by the Non-Insured Health Benefits (NIHB) program administered by Health Canada. By the end of the 20142015 fiscal year, there were 779,300 eligible First Nations individuals and 44,733 eligible Inuit under NIHB (Health Canada 2016), constituting 2.3\% of the Canadian population. For services falling under the scope of Medicare, registered Indians and recognized Inuit rely on provincial and territorial plans, but for services beyond Medicare, they rely on the federal government's NIHB plan.

In this bifurcated policy regime, registered Indians and recognized Inuit are eligible for provincial and territorial Medicare services; however, they are a federal responsibility for nonMedicare coverage for pharmaceuticals, dental care and continuing care (long-term care and home care). This bifurcation of coverage has been cited as an additional burden for this population (Marchildon 2013; Taylor 1987). However, little to no research has been conducted on coverage for conditions, such as obstructive sleep apnea, that require services that are truly on the boundary line between what are treated as universally covered "insured" Medicare services and non-insured services that may be covered under private health insurance or federal or provincial extended health benefit plans. For instance, the management of conditions such as sleep apnea requires physician consultations that are covered by Medicare and treatment using medical equipment that is not covered by Medicare.

Although restricted to hospital and medical services and, therefore, "narrow" in its reach, Canadian Medicare is also deep, in that the 10 provincial and 3 territorial single-payer coverage plans ensure that residents, including all Indigenous residents, have free access to all Medicare services. However, services deemed by provincial and territorial governments to be outside the Medicare basket are subject to different rules. In particular, NIHB-eligible individuals are automatically excluded from access to provincial and territorial extended health benefit coverage and must rely on NIHB or private coverage. 
While the treatments for most respiratory health conditions are considered "insured services" under the Canada Health Act (and therefore part of Medicare), obstructive sleep apnea falls into a grey area. While physician care for sleep apnea falls under Medicare coverage, the medical devices required for treatment appear to be excluded from provincial and territorial Medicare plans. Because the Government of Canada only recognizes registered Indians and recognized Inuit to be within the federal government's NIHB responsibilities, this produces differential coverage within Canadian Indigenous populations (Quiñonez and Lavoie 2009). This case study explores the nature and consequences of this bifurcation of health policy in the province of Saskatchewan based on key informant interviews with federal and provincial program administrators and sleep medicine specialists. Based on the 2011 Census, $15.6 \%$ of the Saskatchewan population is of Indigenous descent, and 96,160 of the province's 103,210 First Nations people were registered and eligible for NIHB benefits, with roughly one-half of this number living on reserves (Statistics Canada 2013).

There are two laboratories in the province of Saskatchewan that conduct Level 1 or complete 15-channel polysomnogram overnight sleep studies. These are located at Saskatoon City Hospital with a capability of six patients/night, five nights/week, and at Regina General Hospital with the capability of four patients/night, five nights/week. Referrals may be made to these laboratories by specialists in respiratory disease or neurology. Only specialists with training and/or possessing specialist certification in sleep medicine may work in sleep laboratories to interpret tests and consult patients following the tests. The waiting lists for non-urgent cases to access these laboratories varies from six to eight months to a year. These tests are provided without charge to all persons including First Nations persons under the Saskatchewan Hospital Services Plan.

Level 3 or home-based sleep studies are available in the province provided by a number of public and private sector organizations with very short waiting periods of days to weeks. These are provided variably without charge or nominal fee to all persons, and are quite mobile, as the equipment is often sent by bus to the patient. Level 3 studies are adequate to make a diagnosis of obstructive sleep apnea in the majority of cases.

\section{Health Inequalities and Obstructive Sleep Apnea}

Overall, in Canada, Indigenous peoples experience a lower standard of living (Wilson and Macdonald 2010) and have a significantly lower life expectancy than other residents in Canada (Statistics Canada 2010). Using the United Nations Human Development Index, Canada consistently ranks within the top five countries in the world, while its Indigenous population ranks approximately $63^{\text {rd }}$ by the same measure (Reading et al. 2007). Within this context of a wide health gap between Indigenous peoples and other people in Canada, sleep apnea occupies a unique position.

Obstructive sleep apnea is the most common type of sleep apnea and manifests from blockage or collapse of the upper airways during sleep, thus causing episodes of apnea or hypopnea. Attempts at breathing during these episodes usually result in snoring and, overall, the condition 
may be associated with poor sleep quality and excessive day-time sleepiness (National Institutes of Health 2012). According to the Public Health Agency of Canada (2009), an estimated 3\% (or approximately 850,000 ) of Canadian adults have been diagnosed with sleep apnea; however, $>25 \%$ of the Canadian adult population is estimated to be undiagnosed sufferers of the condition.

Sleep apnea is frequently associated with overweight or obese weight status, hypertension, metabolic syndrome, diabetes and high cardiovascular risk (National Institutes of Health 2012). Apart from vulnerability to these co-morbidities, individuals diagnosed with sleep apnea are predisposed to higher risk of motor vehicle accidents (Young et al. 1997), low productivity due to excessive daytime sleepiness (Carter et al. 1996), increased healthcare utilization patterns (AlGhanim et al. 2008) and the inevitable economic costs of these various factors.

While sleep apnea prevalence rates in the Indigenous population are currently unavailable, the disproportionately high poor health outcomes in the Indigenous population of Canada (Lix et al. 2009; Reading 2009) make it probable that sleep apnea prevalence is also higher. Indeed, previous research in Northern British Columbia has identified a higher prevalence of low-quality sleep among Indigenous individuals (Froese et al. 2008; Redline et al. 2004). In addition, the co-morbidities of sleep apnea are especially indicative of Indigenous people's susceptibility to sleep apnea because of higher morbidity and mortality rates from these co-morbidities among Indigenous populations (Lix et al. 2009; Reading 2009).

These unequal health outcomes in Indigenous peoples are linked to deprived access to resources that can be located in proximal social determinants of health such as higher rates of low education attainment, unemployment and poor housing conditions (Elias et al. 2012; Reading and Wien 2009; Reading 1997). As a product of the historical and intergenerational perpetuation of health disparities (Elias et al. 2012; King et al. 2009; Reading 1997; Smith et al. 2005), and as we will argue here using the case of sleep apnea, contemporary conditions of colonization, these differences in determinants and outcomes are ultimately inequitable. This means they are unfair, unjust and avoidable (Braveman 2006).

The health inequities experienced by Indigenous peoples are frequently further magnified by difficulty in access to healthcare because of geographic isolation. Geography is an important determinant of health (Kirby and LeBreton 2002; Ministerial Advisory Council on Rural Health 2002; Romanow 2002) and as "place" is a critical population health variable (Canadian Population Health Initiative 2006). Rural and remote dwelling Indigenous populations face additional challenges. For instance, currently in Saskatchewan, there are only two main (urban) centres for sleep testing and diagnosis: the Sleep Disorders Program in the Saskatoon Health Region (2014) and the Regina Health District Sleep Disorders Centre (Regina Qu'Appelle Health Region 2015). With roughly 50\% of First Nations people living on reserves some distance from urban centres in Saskatchewan (Statistics Canada 2013), it is apparent that more than half of Saskatchewan's First Nations population face geographic barriers in accessing sleep apnea care. Apart from the probability of higher susceptibility to not only sleep apnea but also its co-morbidities, Indigenous peoples in Canada face significant social, economic and geographic barriers in accessing sleep apnea care. 
In this disadvantaged scenario, a bifurcated healthcare policy regime that leads to differential access to extended health benefits between registered Indians and recognized Inuit, and other people in Canada, further perpetuates inequalities that could ultimately magnify already endemic health inequalities.

\section{Historical Context and Continuing Challenges}

Table 1 summarizes the key historical steps that produced a health policy bifurcation for registered Indians in Canada. Federal jurisdiction for First Nations people became part of the Canadian constitution that accompanied the creation of the country in 1867. Within less than a decade, the federal government enacted the Indian Act - the law that has since shaped and regulated the government's relationship with registered Indians and First Nations band governments (Lavoie et al. 2010).

TABLE 1. Historical chronology of bifurcated health policy for Indigenous Canadians

\begin{tabular}{|c|c|}
\hline Year & Event \\
\hline 1763 & $\begin{array}{l}\text { Royal Proclamation establishing legal recognition of Indigenous rights by British Crown and imposing a fiduciary duty of care } \\
\text { on the Crown. }\end{array}$ \\
\hline 1867 & $\begin{array}{l}\text { Canadian Constitution (originally the British North America Act, 1867, now the Constitution Act, 1867) becomes law with the } \\
\text { creation of the Canadian Confederation: established that the federal government has the legislative jurisdiction for "Indians and } \\
\text { lands reserved for the Indians." }\end{array}$ \\
\hline 1876 & Indian Act: defined who was and was not "Indian" based on registration or status. \\
\hline 1945 & Indian and Northern Health Services becomes part of newly formed federal ministry of National Health and Welfare. \\
\hline 1957 & $\begin{array}{l}\text { Health and Diagnostic Services Act: federal law that set national standards for universal hospital coverage at the provincial level } \\
\text { including the requirement that provincial governments make coverage available to all residents, including all indigenous residents } \\
\text { in return for providing 50\% of the cost of coverage. Provincial Governments implemented single-payer hospital plans that met } \\
\text { national standards between } 1958 \text { and } 1961 \text {. }\end{array}$ \\
\hline 1966 & $\begin{array}{l}\text { Medical Care Act: federal law that extended national standards and provided } 50 \% \text { of the cost of coverage for universal medical } \\
\text { care coverage for provincial residents, including indigenous residents. Provincial governments implemented single-payer medical } \\
\text { care coverage plans that met national standards between } 1968 \text { and } 1971 \text {. }\end{array}$ \\
\hline 1969 & $\begin{array}{l}\text { Through the Statement of the Government of Canada on Indian Policy (Trudeau White Paper), the federal government } \\
\text { proposed to abolish the Indian Act, terminate treaties and eliminate the distinct legal status of First Nations. Aboriginal groups, } \\
\text { who felt that the objective was assimilation rather than equality, rejected the proposal. }\end{array}$ \\
\hline 1970s & $\begin{array}{l}\text { Provincial governments fill some of the gaps in Medicare and employment-based private insurance coverage by establishing more } \\
\text { limited and targeted coverage and services for prescription drug therapies, dental care and continuing care (social care). }\end{array}$ \\
\hline 1979 & $\begin{array}{l}\text { Indian Health Policy adopted by the federal government: included amalgamating benefits and services into the Non-Insured } \\
\text { Health Benefits (NIHB) program. }\end{array}$ \\
\hline 1984 & $\begin{array}{l}\text { Canada Health Act passed by the federal Parliament: replaces Health and Diagnostics Services Act and Medical Care Act and locks } \\
\text { in national standard on provincial requirement to cover indigenous residents. }\end{array}$ \\
\hline 1989 & $\begin{array}{l}\text { Health Transfer Policy: beginning of transfers, including funds for health services, under self-government agreements to } \\
\text { indigenous band governments. }\end{array}$ \\
\hline
\end{tabular}

In the twentieth century, the federal government gradually increased its provision of basic hospital, medical and other health services to registered Indians and recognized Inuit. These services were transferred to the newly established Department of National Health and Welfare 
in 1945. By 1955, the Indian and Northern Services in the Department of National Health and Welfare was operating 18 hospitals providing basic acute care and 40 nursing stations, 59 health centres and 27 clinics providing public healthcare and primary care services for 163,500 eligible "Indians and Eskimos" (Department of National Health and Welfare 1956; Lux 2016). However, in the next decade, with the introduction of universal Medicare, the federal government would fundamentally alter its policy of directly providing hospital and medical services to Indigenous people. This position was shaped by the Government of Canada's view that it was under no treaty or constitutional obligation to provide free, universal coverage for health services, as stated in the Department of Health and Welfare's Annual Report of 1956:

To put the relationship between this Service and the Indian population of the country in proper perspective, it must first be emphasized that the Indian is not entitled by law to free medical care. It is the intention of the Government to help these people reach full social, economic, and educational equality with their white neighbours and to assist them, if they choose, to become full partners in the Canadian community. However, they have not been made wards of the State, nor has the State even assumed the responsibility of providing free medical attention to all, irrespective of their legal status or ability to pay. On the other hand, the government votes a certain amount of money to be spent each year for the provision of basic health and treatment services to the Indians and Eskimos. This is done on humanitarian grounds, for the isolation of many of these people is such that even the most primitive facilities would not otherwise be available. (Department of National Health and Welfare 1956: 84)

In 1957, the federal Parliament passed the Hospital Insurance and Diagnostic Services Act. The new law encouraged provincial governments to provide universal hospital coverage under a common set of standards by providing $50 \%$ of the cost of coverage through annual transfers. The question of who was responsible for providing coverage to Indigenous people was one of the most contentious issues during the negotiations leading up to the implementation of universal hospital coverage. Before and during the First Ministers' Conferences and the technical meetings of officials and ministers, when universal coverage was being negotiated, provincial politicians and their advisors insisted that the federal government was responsible for the hospital and medical care of Canada's Indian and Inuit residents (Marchildon 2014).

However, on this issue, the federal government was unyielding throughout the negotiations - it would not cost-share provincial health insurance unless provincial governments included all residents, including registered Indians and recognized Inuit, in their universal coverage plans. Ultimately, the provincial governments had to accept this condition to secure cost-sharing from the federal government (Marchildon 2014). Over the next two decades, the federal government would close its "Indian hospitals" or transfer the hospitals to provincial governments (Lux 2016; Waldram et al. 2006). One decade later, when universal coverage was extended to include medical care, defined as physician services at the time, the same 
dispute between the two orders of government emerged. Once again, the provincial governments reluctantly agreed to provide universal medical care coverage to their respective Indigenous populations as stipulated in the Medical Care Act of 1966.

The narrow definition of Medicare resulted in major gaps in service and coverage. From the mid- to late-1970s, provincial governments introduced a number of disparate coverage programs and services that tended to provide highly targeted rather than universal coverage. These gap-fillers included basic drug coverage plans aimed at social assistance recipients and retirees, groups that did not have access to employment-based private health insurance (Boychuk 1998). Some provincial governments experimented with school-based dental plans for children (Mathu-Muju et al. 2013). Almost all provinces introduced means-based subsidies to cover nursing care and accommodation in long-term care facilities. However, these extended health benefits - so called because they extended beyond Medicare coverage - were not provided to eligible Indigenous residents, as they were already receiving some extended health benefits through the Department of National Health and Welfare.

With the introduction of the Indian Health Policy in 1979, these extended health benefits were formally organized under the NIHB program, providing coverage to registered Indians and recognized Inuit for prescription drugs, dental care, medical travel and other extended (non-Medicare) health benefits.

Since then, a registered Indian in Canada has two policy numbers for health coverage. The first is a provincial health number (and card) for Medicare and the second is a federal registration number (and card) from the Department of Aboriginal Affairs and Northern Development Canada that automatically qualifies the individual to be an "eligible recipient" of NIHB. The subsequent passage of the Canada Health Act in 1984 and the Health Transfer Policy, first announced in 1986, which has allowed for a certain degree of self-government in the funding and administration of healthcare by First Nations band governments, has not altered this regime in any fundamental respect (Lavoie 2004).

Aside from the confusion it creates for those defined as registered Indians and recognized Inuit and their health providers, there are many continuing challenges created by the policy bifurcation. It creates incentives for cost shifting between the federal and provincial governments and further between government and private health insurers. Provincial and territorial governments tend to deem registered Indians and recognized Inuit as non-eligible for extended coverage and services because they already obtain benefits from federal coverage. At the same time, the federal government insists that NIHB recipients are only eligible for coverage for specific services if they do not have coverage under a private or provincial healthcare plan or program.

By researching obstructive sleep apnea diagnostic and treatment care, we sought to better understand the implications of health policy bifurcation as understood by the administrators of federal and provincial programs and healthcare providers. In exploring these perceptions, we identify areas of agreement and disagreement among these stakeholder groups and assess the implications for potential future policy change. 


\section{Methods}

A review of federal and provincial government websites using key words and search bars was first undertaken to determine specific policy differences among federal and Saskatchewan government programs for the diagnosis and treatment of sleep apnea. Largely based on federal and provincial legislation, as well as publicly available government documents, this review informed the development of three interview guides for identification and exploration of policy and practice issues among the three key interviewee groups: (1) federal government NIHB program administrators; (2) Saskatchewan government extended benefits program administrators; and (3) sleep medicine specialists responsible for the diagnosis and treatment of sleep apnea. A semi-structured format was used to allow for a broader discussion of issues related to the delivery of health services to patients legally defined as registered Indians.

A snowball recruitment technique was used to recruit interview participants. Contact persons were identified using online government department directories and pre-existing contacts of the researchers. Initial recruitment involved e-mail and telephone contact, and these initial contacts were asked to suggest other potential interview participants. In total, 16 individuals were initially contacted to participate, of which eight felt they were not appropriate to respond from their organization based on their limited involvement in the area of sleep apnea benefits; in those cases, the researchers were instead directed to one or more appropriate individuals who participated on behalf of their organization.

In total, 10 interviews were conducted between September 17, 2014, and November 26, 2014, including federal government NIHB administrators $(n=3)$, Saskatchewan government extended benefit administrators $(n=4)$ and sleep medicine physicians $(n=3)$. The inclusion criteria for government program administrators included the following: (1) having a working knowledge of the policies or procedures related to accessing sleep apnea care in Saskatchewan and (2) being a current employee of the respective provincial/federal government department. The inclusion criteria for sleep medicine physicians included the following: (1) being a practising sleep medicine specialist working in Saskatoon or Regina and (2) having experience treating both NIHB-eligible First Nations patients and other Saskatchewan residents.

Interviews were 30-60 min in length and were conducted in person, with the exception of one telephone interview. All interviews were audio-recorded, transcribed verbatim and deidentified. Participants were offered the opportunity to withdraw portions of their interview transcript so as to reduce any potential risks or repercussions to their employment. Thematic analysis was then carried out on the transcripts using a priori coding based on an extensive review of the secondary and grey literature in combination with inductive coding based on the lead researcher's judgment and knowledge of the content of the interviews. NVIVO software was used for ease and accuracy of coding. Interview participants provided informed consent at the time of interview. Ethical approval was obtained from the University of Regina and University of Saskatchewan respective research ethics boards. 


\section{Results and Discussion}

The specific differences between service coverage and procedures to access benefits for the respective provincial and federal sleep apnea benefit programs were identified through a literature review (Figure 1). Although both programs provide coverage for the recognized gold-standard treatment of sleep apnea known as continuous positive airway pressure (CPAP) therapy, the eligibility requirements for access to CPAP therapy differ. Provincial coverage is based on CPAP prescription by a Saskatchewan-based respirologist (Government of Saskatchewan 2014), whereas NIHB coverage has historically specified that the gold standard Level 1 test is required to confirm diagnosis (Health Canada 2009). In Saskatchewan, Level 1 testing is conducted exclusively in hospital-based laboratories. A Level 1 test conducted in a laboratory includes 15 channels of information, including electroencephalogram, eye movement, chin tone, leg movements, intercostal muscle movements, electrocardiogram signal, oximetry as a measure of oxygen saturation, two channels measuring air movement at the nose and mouth, motion of the chest and abdomen and a record of snoring. In addition, when monitoring treatment, measurement of airflow in a CPAP mask may replace the air movement channels at the nose and mouth, and pressure(s) within the mask may be monitored. In Saskatchewan, the in-hospital cost of a Level 1 study for First Nations and others is borne by the provincial paying agency, which is the Saskatchewan Hospital Services Plan.

In a Level 3 study, which may be conducted for one night in the home, a simplified set of measurements includes air movement at the nose and mouth, oximetry measured on the finger, a record of pulse and a record of snoring. In certain situations, it may be necessary to refer a patient who has had a Level 3 test to a more advanced laboratory, which, in Saskatchewan, is located in hospitals for a Level 1 test. The medical reasons for this could include uncertainty of diagnosis or complexity of the condition. However, the majority of cases of obstructive sleep apnea can be diagnosed and treated with Level 3 home testing.

It is now becoming common for insuring agencies to authorize the provision of CPAP treatment equipment on the basis of a Level 3 study with the obvious advantages of ease and low cost. For example, in the US, both Medicare and Medicaid programs authorize payment for treatment equipment on the basis of Level 3 studies. Level 3 studies may be obtained in Saskatchewan by several methods, including free-of-charge, through the Saskatoon Health District, and through several private sector companies in the largest urban centres that charge a nominal amount or perform the test free of charge. In addition, the private sector companies will send the equipment to rural clients outside Saskatoon by bus for home testing.

Thus, in many cases, provincial residents may obtain treatment on the basis of the lowerlevel and readily available Level 3 study conducted one night at home, which often is available to the client within days. On the other hand, NIHB-eligible residents (i.e., registered Indians) have been required to go through the advanced Level 1 testing in a hospital laboratory with waiting lists that, except in urgent cases, may vary from six months to over one year. This problem is compounded by the fact that many registered Indian clients must travel 
from rural and remote areas. NIHB also requires a relatively complex process that involves the necessity of renting an insured CPAP machine for three months, after which clients must provide medical proof of adherence before they will qualify for insured CPAP purchase.

With regard to payment, provincial residents (except for those who are NIHBeligible) are issued a CPAP machine long-term lend without charge through the Saskatchewan Aids to Independent Living (SAIL) program. The individual client is responsible for completing the package of necessary equipment by the purchase of mask, tubing and heated humidity, the cost of which can be reimbursed by personal insurance programs or are covered by existing programs for social service recipients. For NIHB-eligible residents, following the in-laboratory Level 1 study, three-month rental program and the 'medical proof of adherence' requirement, NIHB covers the machine, mask, tubing and humidity.

FIGURE 1. CPAP pathway for NIHB and SAIL beneficiaries in Saskatchewan

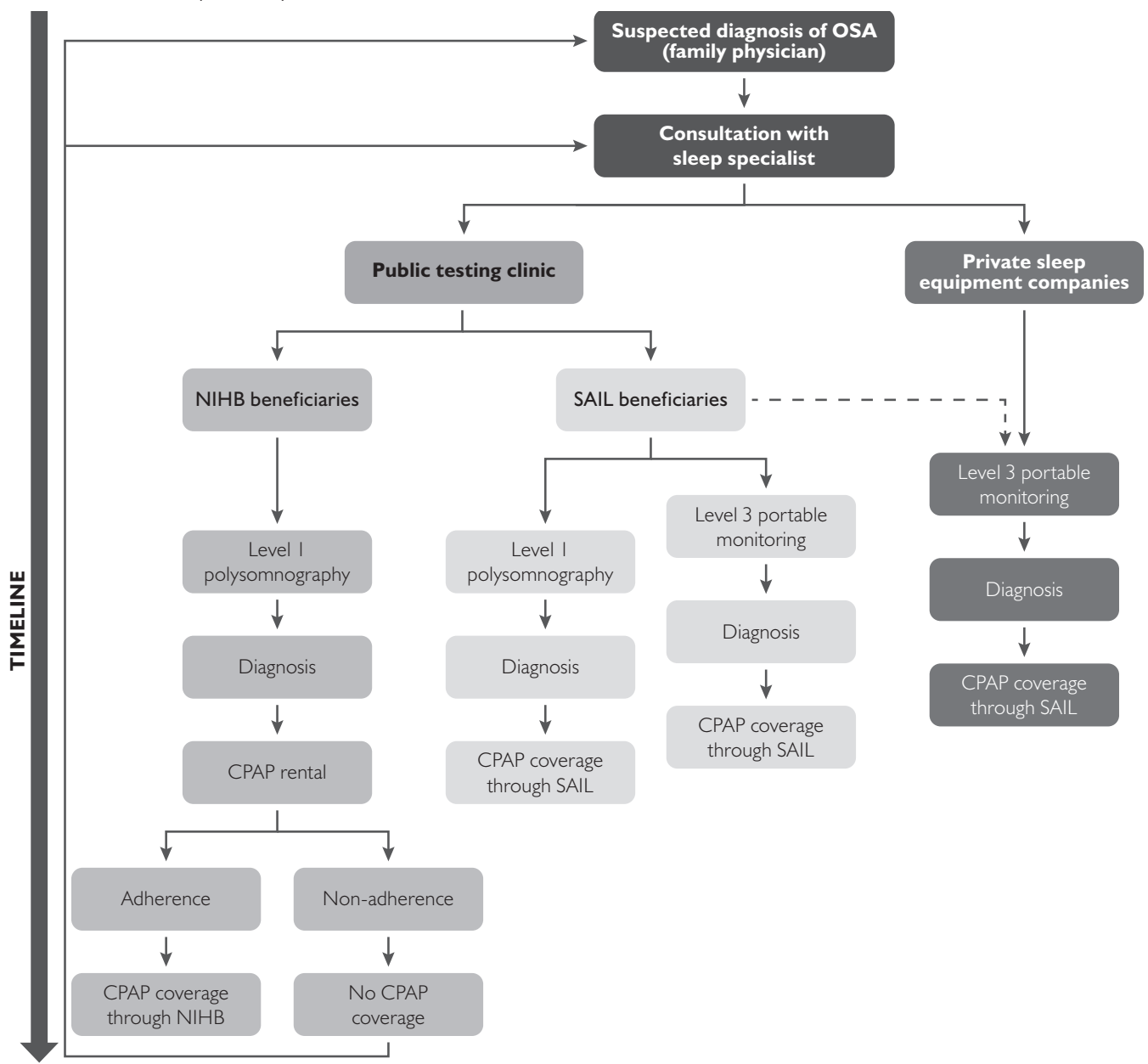

CPAP = continuous positive airway pressure; $\mathrm{NIHB}=$ non-insured health benefits; OSA = obstructive sleep apnea; SAIL = Saskatchewan Aids to Independent Living. Note: Upon diagnosis, a patient with sleep apnea may decide to forego public coverage provided through NIHB or SAIL and instead purchase a CPAP machine directly from a private respiratory equipment provider. 
Although they recognized that both programs ultimately provide CPAP coverage, sleep apnea specialists consider procedural differences a barrier to care for NIHB-eligible patients. Moreover, these physicians described the frustration among their patients in accessing health benefit programs and coordinating benefits among multiple programs:

"I know they won't get funded for a CPAP machine if I send them for Level 3 testing, regardless who's providing it, right? So I actually preferentially send people with a Treaty [registration] number for Level 1 polysomnography because I know that it's going to be an administrative mess for them to try and get a CPAP machine if I don't do that. It's just a way of facilitating care for them" (Sleep Medicine Specialist \#2).

In addition to these administrative delays, the sleep medicine specialists pointed out that even greater challenges are created because of the geographic isolation of rural and remote reserve communities. Even accessing Level 1 diagnosis is a significant barrier because of the travel, costs and extended time commitments.

Federal and Saskatchewan government program administrators were not familiar with all the federal-provincial differences in program requirements for diagnosis and treatment of sleep apnea. Although they had episodic knowledge of some programmatic differences and could provide examples of some service gaps created by this federal-provincial divide, they could not provide a systematic comparison of coverage.

For federal program administrators, eligibility for services is based on NIHB being a "payer of last resort," meaning that eligible individuals can only access coverage for services when these services are not insured by other public and private plans, including provincial extended benefit plans. In this view, NIHB coverage is administered on the basis of the coverage of a specific service for a specific beneficiary rather than on the basis of full eligibility for all services based on registered Indian or recognized Inuit status. In this approach, a detailed review of each individual claim submitted to NIHB is required to determine eligibility.

Alternatively, provincial government administrators determined eligibility on a more universal basis through a process of automatic exclusion. Based on provincial regulation, NIHB-eligible patients are automatically deemed ineligible for provincial extended health benefits. This presents a burden where a specific health benefit is available under a provincial program but is not offered under the federal regime, and NIHB-eligible patients pay out of pocket or through private health insurance or go entirely without the service.

[Regarding a specific benefit,] the [provincial] program might say, "Well, we do provide this, but because they're [registered Indians] First Nations [sic], we think that you should be providing this through NIHB," and NIHB will say, "But it's excluded. This piece of equipment we don't even provide." So the clients end up getting stuck in the middle of that, right, so sometimes it's not so much based on benefits, it's based on Status. (Federal program administrator \#3) 
Both provincial and federal program administrators recognize the benefits of collaboration to remedy issues of access. However, intergovernmental cooperation has been limited despite Jordan's Principle. In 2007, the House of Commons passed a general resolution on the principle which declared that when jurisdictional disputes occur regarding the responsibility for a First Nations child's health or social care, the government at first point of contact should pay in order to avoid delays in care, and the two governments negotiate fiscal responsibility afterward. However, operational implementation of Jordan's Principle through federal-provincial collaboration has been extremely limited (Jordan's Principle Working Group 2015; MacDonald 2007). Despite the fact that over a decade has elapsed since Jordan's Principle was enunciated, there has been little communication, much less collaboration, between federal and provincial on services such as obstructive sleep apnea, an admittedly difficult area because the condition involves the mixture of "insured services" under the Canada Health Act and services under federal and provincial extended health benefit coverage schemes. And where collaboration has occurred on a range of health services, it has tended to address problems after they arise rather than proactively seeking to prevent problems (Blackstock 2016). Federal program administrators in particular noted the challenges involved in aligning the Canada-wide NIHB program with highly variable provincial extended health benefit programs.

Perhaps because they were aware of some of the complexities of federal-provincial relations on Indigenous policy in general, and health policy in particular, the interviewees offered few policy solutions. However, sleep medicine providers expressed interest in federal and provincial governments reconciling funding issues to streamline service delivery and coverage. This was perceived as a way to eliminate differences in service coverage, reduce delays in treatment and lessen the administrative frictions on patients and providers.

\section{Conclusion and Policy Implications}

For historical and constitutional reasons, most registered Indians and recognized Inuit in Canada encounter a bifurcated health regime in Canada. Although little research has been conducted on the implications of this policy bifurcation for people trying to access a health service, this case study on sleep apnea suggests that there may be additional burdens that may serve to exacerbate, rather than diminish, existing inequities in health outcomes. While more research is required in other areas of extended health benefits and services, these results suggest a health policy impasse that should be addressed.

In the past, policy options to reduce inequities in health and social services for Indigenous populations have been proposed, although to little or no avail. One approach used by the federal government was to transfer funding for health and other services directly to First Nations governments. Although this was to have permitted a degree of Indigenous self-government, expertise was not transferred and relatively small Indigenous governments were forced to navigate the funding and administration of inherently complex services without the requisite capacity. This problem was exacerbated by the fact that the funds were not increased sufficiently over time. 
Using a re-structuring approach, the 2002 Romanow Commission on the Future of Health Care in Canada called for the consolidation of existing funding from all levels of government into single Aboriginal health budgets to allow for greater integration and partnership (Romanow 2002). This recommendation has not yet been examined carefully by governments in Canada, and much might be gained if the council of federal, provincial and territorial ministers or deputy ministers of health struck a working group to assess the viability of such an approach.

There are other policy approaches that could be considered. For example, the federal government could undo its original agreement with the provinces on Medicare and create a new First Nations and Inuit health policy based on the delivery of services by an emerging order of Indigenous governments (Lavoie 2013). However, even if a broad intergovernmental and societal consensus could be reached on the general principles, much less the specific organizational details, of such an approach, it would take a generation or more to implement due to the complexities of the financial and administrative arrangements, and the time required by Indigenous governments to build the requisite administrative and service delivery capacity. Moreover, due to the enormous fiscal risk that such a change implies for the federal government, it is difficult for any federal administration, including the current Trudeau government, which has promised major changes in its relationship with Indigenous peoples in Canada, to pursue this change.

For this reason, it would be worth considering more immediate policy options. One option is for the federal government to realign NIHB coverage to match extended benefits coverage in each province so that diagnosis and treatment is largely the same in each province. The benefit is that all provincial residents, including NIHB-eligible residents, would, in theory, receive identical diagnosis and treatment depending on the province of residence. However, coverage would depend on the province of residence, and it is possible that provincial coverage in at least some jurisdictions likely falls beneath the coverage offered by NIHB at this time - something that could be further investigated.

A more radical option is for a renegotiation of the original federal-provincial compact on Medicare, which would expand the definition of insured services to include at least some of the non-insured services currently covered by NIHB - particularly those such as sleep apnea, which are disease entities not recognized at the time of the original agreements. This would likely require an increase in the federal government's cash transfers to provincial governments. While more radical, it would certainly clarify current responsibilities between the two orders of government and create a single pipeline for the financing and delivery of medically necessary health services. On the other hand, it would also weaken the accountability linkage between the federal government and Indigenous peoples and may make it more difficult to achieve a self-government approach to health service delivery by First Nations governments and communities. While provincial and territorial governments currently may have few reasons at this time to align their extended health benefit schemes, the federal government might be able to provide the financial incentive to encourage some national-level standard setting. 


\section{Notes}

1. Registered Indians are Indigenous individuals who hold a certificate of Indian status with the federal government of Canada.

2. The Inuit traditionally lived above the tree line of current day Canada and are part of a larger circumpolar Inuit population that includes Greenland, Alaska and Russia. Recognized Inuit are individuals who are recognized by one of the Inuit land claim organizations. The legal language of "registered Indian" and "recognized Inuit" is used throughout this article to avoid confusion with non-registered Indians, Métis and nonrecognized Inuit who are excluded from NIHB coverage and, therefore, eligible for provincial and territorial extended health benefit coverage.

Correspondence may be directed to: Gregory P. Marchildon, Institute of Health Policy, Management and Evaluation, University of Toronto, 155 College Street, Suite 425, Toronto, ON M5T3M6; e-mail:greg.marchildon@utoronto.ca.

\section{References}

AlGhanim, N., V.R. Comondore, J. Fleetham, C.A. Marra and N.T. Ayas. 2008. “The Economic Impact of Obstructive Sleep Apnea." Lung 186: 7-12.

Blackstock, C. 2016. “Toward the Full and Proper Implementation of Jordan's Principle: An Elusive Goal to Date." Paediatrics \& Child Care 21(5): 245-46.

Boychuk, G.W. 1998. Patchworks of Purpose: The Development of Social Assistance Regimes in Canada. Montreal, QC: McGill-Queen's University Press.

Braveman, P. 2006. "Health Disparities and Health Equity: Context and Measurement." Annual Review of Public Health 27: 167-94.

Canadian Population Health Initiative. 2006. How Healthy Are Rural Canadians? An Assessment of Their Health Status and Health Determinants. Ottawa, ON: Canadian Institute for Health Information.

Carter, N., C. Edling, M. Talback and J. Ulfberg. 1996. “Excessive Daytime Sleepiness at Work and Subjective Work Performance in the General Population and Heavy Snorers and Patients with Obstructive Sleep Apnea." Chest 110(3): 659.

Department of National Health and Welfare. 1956. Annual Report for the Fiscal Year Ended March 31, 1956. Ottawa, ON: Queen's Printer.

Elias, B., J. Mignone, M. Hall, S. Hong, L. Hart and J. Sareen. 2012. “Trauma and Suicide Behaviour Histories among a Canadian Indigenous Population: An Empirical Exploration of the Potential Role of Canada's Residential School System." Social Science and Medicine 74: 1560-69.

Froese, C.L., A. Butt, A. Mulgrew, R. Cheema, M. Speirs, C. Gosnell, et al. 2008. “Depression and Sleep-Related Symptoms in an Adult, Indigenous, North American Population." Journal of Clinical Sleep Medicine 4(4): 356-61.

Government of Saskatchewan. 2014. Drug Plan and Extended Benefits Branch: Saskatchewan Aids to Independent Living (SAIL) General Policies. Regina, SK: Government of Saskatchewan. Retrieved April 17, 2015. <http:// www.health.gov.sk.ca/adx/aspx/adxGetMedia.aspx?DocID=2894,94,88,Documents\&MediaID=4716\&Filena $\mathrm{me}=$ sail-general-policies-jan-2011.pdf\&l=English $>$.

Gracey, M. and M. King. 2009. “Indigenous Health Part 1: Determinants and Disease Patterns." Lancet 374: 65-75. doi:10.1016/S0140-6736(09)60914-4.

Health Canada. 2009. Non-Insured Health Benefits: Provider Guide for Medical Supplies and Equipment (MSEE) Benefits. Ottawa, ON: Health Canada. Retrieved April 17, 2015. <http://www.hc-sc.gc.ca/fniah-spnia/pubs/ nihb-ssna/_medequip/2009-prov-fourn-guide/index-eng.php>. 
Health Canada. 2016. Non-Insured Health Benefits Program: Annual Report 2014/2015. Ottawa, ON: First Nations and Inuit Health Branch, Health Canada.

Health Canada. 2017. Canada Health Act Annual Report 2015-2016. Ottawa, ON: Author.

King, M., A. Smith and M. Gracey. 2009. "Indigenous Health Part 2: The Underlying Causes of the Health Gap." Lancet 374: 76-85.

Kirby, M. and M. LeBreton. 2002. The Health of Canadians: The Federal Role, Volume 6, Recommendations for Reform. Ottawa, ON: The Senate of Canada.

Lavoie, J.G. 2004. "The Values and Challenges of Separate Services: First Nation in Canada." In J. Healy and M. McKee, eds., Accessing Healthcare: Responding to Diversity. Oxford, UK: Oxford University Press.

Lavoie, J.G. 2013. “Policy Sciences: Why Canada Needs a National First Nations, Inuit and Métis Health Policy." International Journal of Circumpolar Health 72: 22690. doi:10.3402/ijch.v72i0.22690.

Lavoie, J.G., E.L. Forget and A.J. Browne. 2010. "Caught at the Crossroad: First Nations, Health Care, and the Legacy of the Indian Act." Pimatisiwin: A Journal of Aboriginal and Indigenous Community Health 8: 83-99.

Lix, L.M., S. Bruce, J. Sarkar and T.K. Young. 2009. "Risk Factors and Chronic Conditions among Aboriginal and Non-Aboriginal Populations." Health Reports 20(4): 21-29.

Lux, M. 2016. Separate Beds: A History of Indian Hospitals in Canada, 1920s-1980s. Toronto, ON: University of Toronto Press.

MacDonald, N. 2007. “Jordan’s Principle, Governments' Paralysis.” CMAJ 177(4): 321.

Marchildon, G.P. 2013. "Canada: Health System Review." Health Systems in Transition 15(1): 1-179.

Marchildon, G.P. 2014. "The Three Dimensions of Universal Medicare in Canada." Canadian Public Administration 57(3): 362-82.

Mathu-Muju, K.R., J.W. Friedman and D.A. Nash. 2013. “Oral Health Care for Children in Countries Using Dental Therapists, School-Based Programs, Contrasted with that of the United States, Using Dentists in a Private Practice Model." American Journal of Public Health 103(9): e7-e13.

Ministerial Advisory Council on Rural Health. 2002. Rural Health in Rural Hands: Strategic Directions for Rural, Remote, Northern and Aboriginal Communities. Guelph, ON: Rural Ontario Institute.

National Institutes of Health. 2012. What is Sleep Apnea? Retrieved March 6, 2014. <http://www.nhlbi.nih. gov/health/health-topics/topics/sleepapnea/>.

Public Health Agency of Canada. 2009. What is the Impact of Sleep Apnea on Canadians? Fast Facts from the 2009 Canadian Community Health Survey - Sleep Apnea Rapid Response. Ottawa, ON: Public Health Agency of Canada. Retrieved March 6, 2014. <http://www.phac-aspc.gc.ca/cd-mc/sleepapnea-apneesommeil/pdf/sleep-apnea.pdf>.

Quiñonez, C.R. and J.G. Lavoie. 2009. "Existing on a Boundary: The Delivery of Socially Uninsured Health Services to Aboriginal Groups in Canada." Humanity and Society 33: 35-55. doi:10.1177/016059760903300104.

Reading, J. 1997. "Chapter 2: An Examination of Residential Schools and Elder Health." In First Nations and Inuit Regional Health Survey. Ottawa, ON: First Nations and Inuit Regional Health Survey National Steering Committee.

Reading, J. 2009. The Crisis of Chronic Disease among Aboriginal Peoples: A Challenge for Public Health, Population Health and Social Policy. Victoria, BC: University of Victoria. Retrieved June 2, 2015. <http://cahr. uvic.ca/nearbc/documents/2009/CAHR-B2-Chronic-Disease.pdf>.

Reading, C.L. and E. Wien. 2009. Health Inequalities and Social Determinants of Aboriginal Peoples' Health. Prince George, BC: National Collaborating Centre for Aboriginal Health.

Reading, J.L., A. Kmetic and V. Gideon. 2007. First Nations Holistic Policy and Planning Model: AFN Discussion Paper for the World Health Organization Commission on Social Determinants of Health. Retrieved March 7, 2014. <http://ahrnets.ca/files/2011/02/AFN_Paper_2007.pdf>.

Redline, S., H.L. Kirchner, S.F. Quan, D.J. Gottlieb, V. Kapur and A. Newman. 2004. "The Effects of Age, Sex, Ethnicity, and Sleep-Disordered Breathing on Sleep Architecture." Archives of Internal Medicine 164(4): 406-18. 
Regina Qu'Appelle Health Region. 2015. In Hospital Care: Sleep Disorders. Retrieved June 8, 2015. <https:// www.rqhealth.ca/programs/in_hospital_care/sleep_disorders/sleep_disorders.shtml>.

Romanow, R.J. 2002. Building on Values: The Future of Health Care in Canada - Final Report. Ottawa, ON: Commission on the Future of Health Care in Canada.

Saskatoon Health Region. 2014. Sleep Disorders Centre: About Us. Retrieved June 8, 2015. <https://www. saskatoonhealthregion.ca/locations_services/Services/cdm/Pages/Programs/About-Sleep-Disorders-Center.aspx>.

Smith, D., C. Varcoe and N. Edwards. 2005. "Turning Around the Intergenerational Impact of Residential Schools on Aboriginal People: Implications for Health Policy and Practices." Canadian Journal of Nursing Research 7(4): 38-60.

Statistics Canada. 2010. Life Expectancy. Retrieved March 7, 2014. <http://www.statcan.gc.ca/pub/89645-x/2010001/life-expectancy-esperance-vie-eng.htm>.

Statistics Canada. 2013. Aboriginal Peoples in Canada: First Nations People, Métis and Inuit - National Household Survey, 2011. Ottawa, ON: Author.

Taylor, M.G. 1987. Health Insurance and Canadian Public Policy: The Seven Decisions that Created the Canadian Healthcare System (2nd ed.). Montreal, QC: McGill-Queen's University Press.

The Jordan's Principle Working Group. 2015. Without Denial, Delay, or Disruption: Ensuring First Nations Children's Access to Equitable Services through Jordan's Principle. Ottawa, ON: Assembly of First Nations. Retrieved April 17, 2015. <http://www.afn.ca/uploads/files/jordans_principle-report.pdf>.

Waldram, J., D.A. Herring and T.K. Young. 2006. Aboriginal Health in Canada: Historical, Cultural and Epidemiological Perspectives (2nd ed.). Toronto, ON: University of Toronto Press.

Wilson, D. and D. Macdonald. 2010. The Income Gap between Aboriginal Peoples and the Rest of Canada. Ottawa, ON: Canadian Centre for Policy Alternatives.

Young, T., J. Blustein, L. Finn and M. Palta. 1997. “Sleepiness, Driving, and Accidents: Sleep-Disordered Breathing and Motor Vehicle Accidents in a Population-Based Sample of Employed Adults." Sleep 20(8): 608-13.

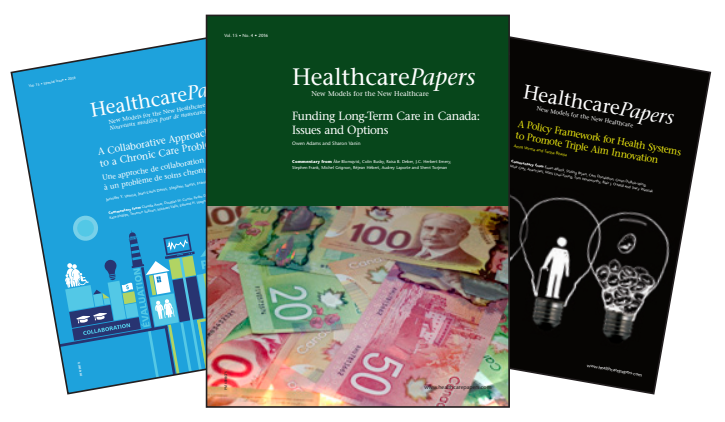

Bridging the gap between academia and the world of healthcare management and policy HealthcarePapers.com 